GLASTOO FUtGR:

葛

要

$H$

点

点
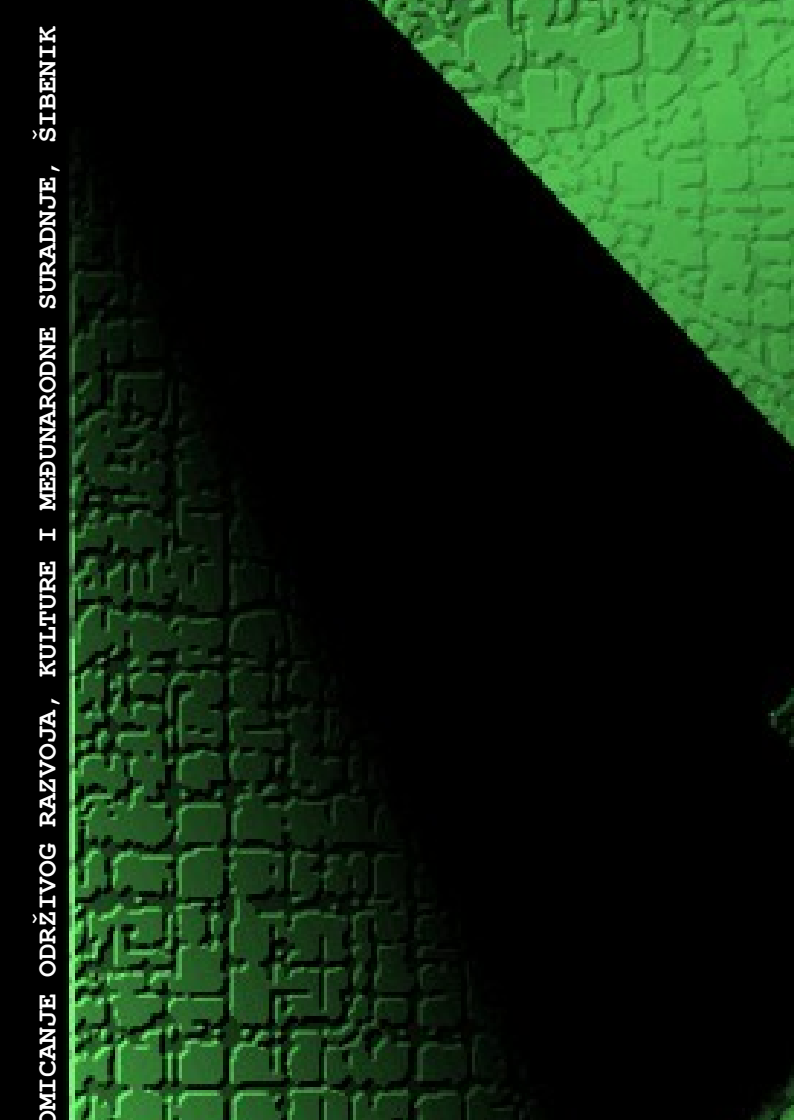


\section{Glasilo Future}

\section{Stručno-znanstveni časopis}

Nakladnik:

FUTURA

\section{FuTU}

Sjedište udruge: Šibenik
Adresa uredništva:

Bana Josipa Jelačića 13 a, 22000 Šibenik, Hrvatska / Croatia

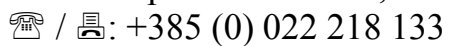

凶: urednistvo@gazette-future.eu / editors@gazette-future.eu (7): www.gazette-future.eu

Uređivački odbor / Editorial Board:

Doc. dr. sc. Boris Dorbić, v. pred. - glavni i odgovorni urednik / Editor-in-Chief

Emilija Friganović, dipl. ing. preh. teh., v. pred. - zamjenica g. i o. urednika / Deputy Editor-in-Chief

Ančica Sečan Matijaščić, mag. act. soc. - tehnička urednica / Technical Editor

Antonia Dorbić, mag. art. - zamjenica tehničke urednice / Deputy Technical Editor

Prof. dr. sc. Željko Španjol

Mr. sc. Milivoj Blažević

Vesna Štibrić, dipl. ing. preh. teh.

Međunarodno uredništvo / International Editorial Board:

Prof. dr. sc. Kiril Bahcevandziev - Portugalska Republika (Instituto Politécnico de Coimbra)

Prof. dr. sc. Martin Bobinac - Republika Srbija (Šumarski fakultet Beograd)

Prof. dr. sc. Zvezda Bogevska - Republika Sjeverna Makedonija (Fakultet za zemjodelski nauki i hrana Skopje)

Dario Bognolo, mag. ing. - Republika Hrvatska (Veleučilište u Rijeci)

Prof. dr. sc. Agata Cieszewska - Republika Poljska (Szkoła Główna Gospodarstwa Wiejskiego w Warszawie)

Dr. sc. Bogdan Cvjetković, prof. emeritus - Republika Hrvatska (Agronomski fakultet Zagreb)

Prof. dr. sc. Duška Ćurić - Republika Hrvatska (Prehrambeno-biotehnološki fakultet Zagreb)

Prof. dr. sc. Margarita Davitkovska - Republika Sjeverna Makedonija (Fakultet za zemjodelski nauki i hrana Skopje)

Prof. dr. sc. Dubravka Dujmović Purgar - Republika Hrvatska (Agronomski fakultet Zagreb)

Prof. dr. sc. Josipa Giljanović - Republika Hrvatska (Kemijsko-tehnološki fakultet u Splitu)

Prof. dr. sc. Semina Hadžiabulić - Bosna i Hercegovina (Agromediteranski fakultet Mostar)

Prof. dr. sc. Péter Honfi - Mađarska (Faculty of Horticultural Science Budapest)

Prof. dr. sc. Valeria Ivanova - Republika Bugarska (Fakultet za lozaro - gradinarstvo Plovdiv)

Prof. dr. sc. Mladen Ivić - Bosna i Hercegovina (Univerzitet PIM)

Doc. dr. sc. Orhan Jašić - Bosna i Hercegovina (Filozofski fakultet Tuzla)

Prof. dr. sc. Tajana Krička - Republika Hrvatska (Agronomski fakultet Zagreb)

Doc. dr. sc. Dejan Kojić - Bosna i Hercegovina (Univerzitet PIM)

Slobodan Kulić, mag. iur. - Republika Srbija (Srpska ornitološka federacija i Confederation ornitologique mondiale)

Prof. dr. sc. Biljana Lazović - Crna Gora (Biotehnički fakultet Podgorica)

Prof. dr. sc. Branka Ljevnaić-Mašić - Republika Srbija (Poljoprivredni fakultet Univerziteta u Novom Sadu)

Doc. dr. sc. Zvonimir Marijanović - Republika Hrvatska (Kemijsko-tehnološki fakultet u Splitu)

Doc. dr. sc. Ana Matin - Republika Hrvatska (Agronomski fakultet Zagreb)

Prof. dr. sc. Bosiljka Mustać - Republika Hrvatska (Sveučilište u Zadru)

Hrv. akademik prof. dr. sc. Stanislav Nakić - Bosna i Hercegovina (Sveučilište Hercegovina Mostar)

Sandra Popović, mag. ing. - Republika Srbija (Poljoprivredni fakultet Beograd)

Doc. dr. sc. Bojan Simovski - Republika Sjeverna Makedonija (Fakultet za šumarski nauki, pejzažna arhitektura i

ekoinženering "Hans Em" Skopje)

Prof. dr. sc. Davor Skejić - Republika Hrvatska (Građevinski fakultet Zagreb)

Doc. dr. sc. Milan Stanković - Republika Srbija (Univerzitet u Kragujevcu)

Akademik prof. dr. sc. Refik Šećibović - Bosna i Hercegovina (Visoka škola za turizam i menadžment Konjic)

Prof. dr. sc. Andrej Šušek - Republika Slovenija (Fakulteta za kmetijstvo in biosistemske vede Maribor)

Prof. dr. sc. Elma Temim - Bosna i Hercegovina (Agromediteranski fakultet Mostar)

Mr. sc. Merima Toromanović - Bosna i Hercegovina (Biotehnički fakultet Univerziteta u Bihaću)

Doc. dr. sc. Ivana Vitasović Kosić - Republika Hrvatska (Agronomski fakultet Zagreb)

Doc. dr. sc. Ana Vujošević - Republika Srbija (Poljoprivredni fakultet Beograd)

Prof. dr. sc. Vesna Židovec - Republika Hrvatska (Agronomski fakultet Zagreb)

Lektura i grafička priprema: Ančica Sečan Matijaščić, mag. act. soc.

Objavljeno: 31. prosinca 2019. godine.

C̆asopis izlazi u elektroničkom izdanju dva puta godišnje, krajem lipnja i prosinca, a predviđena su i dva interdisciplinarna specijalna izdanja tijekom godine iz STEM i ostalih znanstvenih/umjetničkih područja.

C̆asopis je besplatan. Rukopisi i recenzije se ne vraćaju i ne honoriraju.

Umnožavanje (reproduciranje), stavljanje u promet (distribuiranje), priopćavanje javnosti, stavljanje na raspolaganje javnosti odnosno prerada u bilo kojem obliku nije dopuštena bez pismenog dopuštenja Nakladnika.

Sadržaj objavljen u Glasilu Future može se slobodno koristiti u osobne i obrazovne svrhe uz obvezno navođenje izvora. 


\section{Glasilo Future}

\section{Stručno-znanstveni časopis}

FUTURA - stručno-znanstvena udruga za promicanje održivog razvoja, kulture i međunarodne suradnje, Bana Josipa Jelačića 13 a, 22000 Šibenik, Hrvatska

(2019) 2 (4) 01-74

\section{SADRŽAJ:}

Izvorni znanstveni rad (original scientific paper)

Str.

Žana Delić, Ivana Vuković, T. Svalina, M. Šuste, Emilija Friganović, Mladenka Šarolić,

B. Dorbić

Isparljivi spojevi vina od maline

Volatile compounds of raspberry wines

Emilija Friganović, D. Anić, Ančica Sečan Matijaščić, Mladenka Šarolić, B. Dorbić,

Žana Delić, M. Šuste

Ponašanje i stavovi studenata Veleučilišta "Marko Marulić" u Kninu o funkcionalnim

napitcima

Behavior and attitudes of students of the Marko Marulić Polytechnic of Knin toward

functional beverages

\section{Prethodno priopćenje (preliminary communication)}

E. Delić, B. Dorbić, Nađa Buturović, Azra Bostandžić, Almina Tahirović

Prikaz modela za održavanje terenske nastave iz primijenjene botanike i ekologije

A presentation of a model for teaching field courses in Applied Botany and Ecology

\section{Pregledni rad (scientific review)}

\section{B. Dorbić}

Sanacija i revitalizacija drvoreda bijelog duda (Morus alba L.) na prostoru luka Vrnaža Istočni (središnji) dio luke u Šibeniku

Rehabilitation and revitalization of the white mulberry tree (Morus alba L.) in the area of port Vrnaža - East (central) part of the port in Šibenik

\section{Stručni rad (professional paper)}

\section{Ž. Zrno, Ivana Pintur}

Elementarne funkcije u poljoprivredi

Elementary functions in agriculture

\section{Nekategorizirani rad (uncategorised paper)}

Zdenka Bilušić

Prikaz izložbe

Review of exhibition 


\title{
Elementarne funkcije u poljoprivredi
}

\section{Elementary functions in agriculture}

\author{
Željko Zrno ${ }^{1}$, Ivana Pintur ${ }^{1,2}$
}

stručni rad (professional paper)

doi: $10.32779 /$ gf.2.4.5

\section{Sažetak}

Današnja ekspanzija poljoprivredne proizvodnje nije slučajna. Ona je posljedica primjene matematike. Mnogi procesi u poljoprivredi i općenito u biotehničkim znanostima imaju svoje zakonitosti u kojima se uspostavlja veza između dvije varijable, tj. imamo funkcionalnu ovisnost. $U$ ovom članku obrađene su tipične elementarne funkcije: linearna, kvadratna, eksponencijalna i logaritamska te su dani neki primjeri njihove primjene.

Ključne riječi: funkcija (nultočka, ekstremi, graf, linearna, kvadratna, eksponencijalna, logaritamska), ponuda i potražnja

\begin{abstract}
Today's expansion of agricultural production is no accident. It is the consequence of mathematics applying. Many processes in agriculture and in the biotechnical sciences in general have their own laws in which the relationship between two variables is established, that is, we have functional dependence. This article deals with typical elementary functions: linear, quadratic, exponential and logarithmic, and gives some examples of their application.
\end{abstract}

Keywords: function (zero, extremes, graph, linear, quadratic, exponential, logarithmic), supply and demand

\section{Uvod}

Opće mišljenje je da je matematika problem. Ona je problem upravo kao i slikanje umjetničkih slika ili pisanje književnih djela. Matematiku je potrebno "vidjeti". Određeni problem predstavljaju školski programi koji ne uzimaju u obzir biološki razvoj mozga te djeca jednostavno ne mogu u određenoj dobi nešto shvatiti. Pritisnuti ocjenama, počinje učenje napamet što tijekom vremena stvori određenu odbojnost. Međutim, matematika je nešto što nas okružuje, nešto kao zrak koji dišemo. Brojevi nisu

\footnotetext{
${ }^{1}$ Veleučilište "Marko Marulić" u Kninu, Petra Krešimira IV 30, 22300 Knin, Republika Hrvatska.

*E-mail: zzrno@veleknin.hr

${ }^{2}$ Završena studentica Veleučilišta "Marko Marulić" u Kninu.
} 
samo čudni znakovi. Pretpostavimo da niz od nekoliko brojeva predstavlja jedno slovo. Tada neki realni broj, na primjer broj $\pi$, sadrži sva imena na svijetu, u nekom njegovom segmentu su navedeni segmenti brojeva posloženi tako da se tu nalazi kompletno književno djelo. Zamijenimo li neke brojeve notama, negdje u $\pi$ će se naći i IX simfonija. Ukratko, brojevi i matematika je naš svakodnevni život, naše okruženje. Stoga ne treba čuditi činjenica da matematika ima primjenu i u poljoprivredi. Neki dijelovi matematike su više, a neki manje zastupljeni te će se u ovom radu prikazati onaj dio matematike koji se najčešće koristi u poljoprivredi. U ovom radu, u početku ćemo definirati općenito funkcije, dati osnovne karakteristike funkcija: nultočku, ekstreme, crtanje grafova a zatim ćemo izložiti poznate i dosta česte elementarne funkcije: linearnu, kvadratnu, eksponencijalnu i logaritamsku te dati određene primjene.

\section{Funkcionalna ovisnost}

\section{Pojam funkcije}

Postupak kojim se svakom elementu skupa $A$ pridružuje jedan i samo jedan element skupa B nazivamo funkcijom sa skupa $A$ u skup $B$ i pišemo $f: A \rightarrow B$.

Skup čije elemente preslikavamo nazivamo domenom, a element tog skupa argumentom ili nezavisnom varijablom funkcije $f$.

Skup u koji preslikavamo zovemo kodomenom funkcije, a element tog skupa nazivamo vrijednošću ili zavisnom varijablom.

Ako funkcija $f: A \rightarrow B$ elementu domene $x \in A$ pridružuje element kodomene $y \in B$, tada to zapisujemo u sljedećem obliku:

$y=f(x)$.

Funkciju kojoj je kodomena skup realnih brojeva ili njegov podskup nazivamo realnom funkcijom.

Realna funkcija $f: A \rightarrow B$ svakom elementu domene, $x \in A$, pridružuje broj $y=f(x) \in B$, pa možemo promatrati uređeni par $(x, y)$ kojem smo u koordinatnoj ravnini pridružili točku $T(x, y)$. Skup tako dobivenih točaka predstavlja graf funkcije $f$. Dobivene točke se unose u Kartezijev koordinatni sustav.

Funkciju je moguće zadati na tri načina: formulom, tablicom i grafom.

Kao primjer funkcije zadane formulom možemo dati izraz za izračunavanje puta pri slobodnom padu:

$$
f(t)=\frac{g}{2} \cdot t^{2}
$$


odnosno, u malo poznatijem obliku

$s=\frac{g}{2} \cdot t^{2}$

gdje je g ubrzanje sile teže, koje na zemlji iznosi prosječno $9,8066 \mathrm{~m} / \mathrm{s}^{2}$, a t je vrijeme.

Funkcija zadana tablicom je pogodna za grafički prikaz.

\begin{tabular}{|l|r|r|r|r|}
$x$ & 1 & 2 & 5 & 9 \\
\hline$f(x)$ & 13 & 4 & 8 & 1
\end{tabular}

Zadavanje funkcije grafom je često $u$ tehnici i fizici. Može se prikazivati prijeđeni put u vezi s vremenom, promjenu brzine u ovisnosti o vremenu.

\section{Elementarne funkcije i primjena u poljoprivredi}

Uobičajeno je kod pisanja formula funkcija da je s lijeve strane $\mathrm{f}(\mathrm{x})$ potom dolazi znak jednakosti te $\mathrm{s}$ desne strane nešto što treba obaviti s vrijednosti x da bi se dobio rezultat. Dakle, može biti nešto kao:

$$
\begin{aligned}
& f(x)=a x+b \\
& f(x)=a x^{2}+b x+c \\
& f(x)=a^{x} \\
& f(x)=\log x
\end{aligned}
$$

Prikazane formule nekih funkcija su samo dio funkcija u matematici.

\section{Linearna funkcija}

Definicija linearne funkcije glasi: neka su $k, l$ zadani realni brojevi. Funkciju $f: \mathrm{R} \rightarrow \mathrm{R}$ zadanu formulom $\mathrm{f}(\mathrm{x})=\mathrm{kx}+\mathrm{l}$ nazivamo linearnom funkcijom.

Graf linearne funkcije je pravac. Sada dajemo definiciju rasta odnosno pada funkcije.

Definicija: Neka je $\mathrm{A} \subseteq \mathrm{R}$. Za funkciju $f: \mathrm{A} \rightarrow \mathrm{R}$ kažemo da je rastuća (padajuća) ako za sve vrijednosti $x_{1}$ i $x_{2}$ iz A takve da je $x_{1}<x_{2}$ slijedi $f\left(x_{1}\right) \leq f\left(x_{2}\right)\left[f\left(x_{1}\right) \geq f\left(x_{2}\right)\right]$.

Linearna funkcija je rastuća ako je $\mathrm{k}>0$, odnosno padajuća ako je $\mathrm{k}<0$.

Zamijenimo sada $\mathrm{f}(\mathrm{x})$ sa y i počnimo mijenjati vrijednost $\mathrm{x}$. Dobiti ćemo neke točke. Ako uzmemo da je $\mathrm{k}=1$ i l $=0$, tada su nam i x i y jednaki, te kad to ucrtamo u koordinatni sustav dobivamo sljedeći graf: 


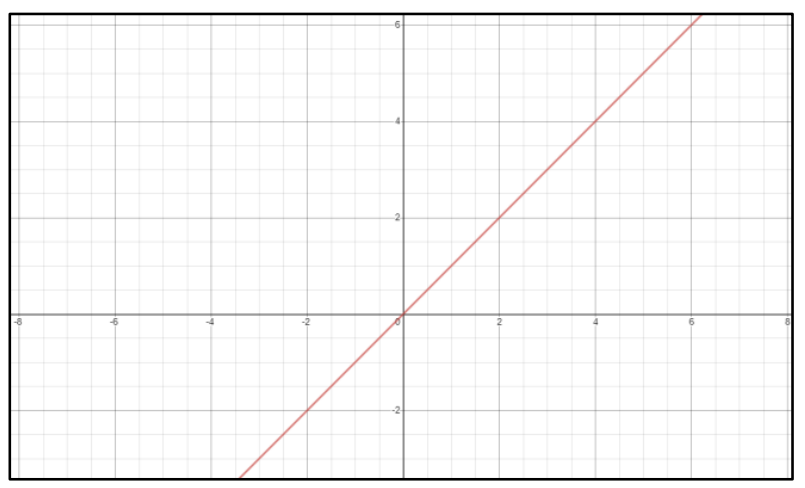

Slika 1. Graf funkcije $f(x)=x$

Figure 1. Function graph $f(x)=x$

Počnemo li mijenjati vrijednosti $l$, uočit ćemo da se graf kreće po osi $y$. Uočavamo da se mijenja nagib pravca - pravac rotira oko koordinatnog početka.

Nacrtajmo graf funkcije $f(x)=-0,5 x+1$.

Dovoljno je odrediti dvije točke koje se nalaze na pravcu koji predstavlja graf zadane funkcije. U tu svrhu uzmimo proizvoljne varijable $x=0$ i $x=2$. Dobivamo: $f(0)=1$ i $f(2)=0$. Dakle, imamo točke $T_{1}(0,1)$ i $T_{2}(2,0)$

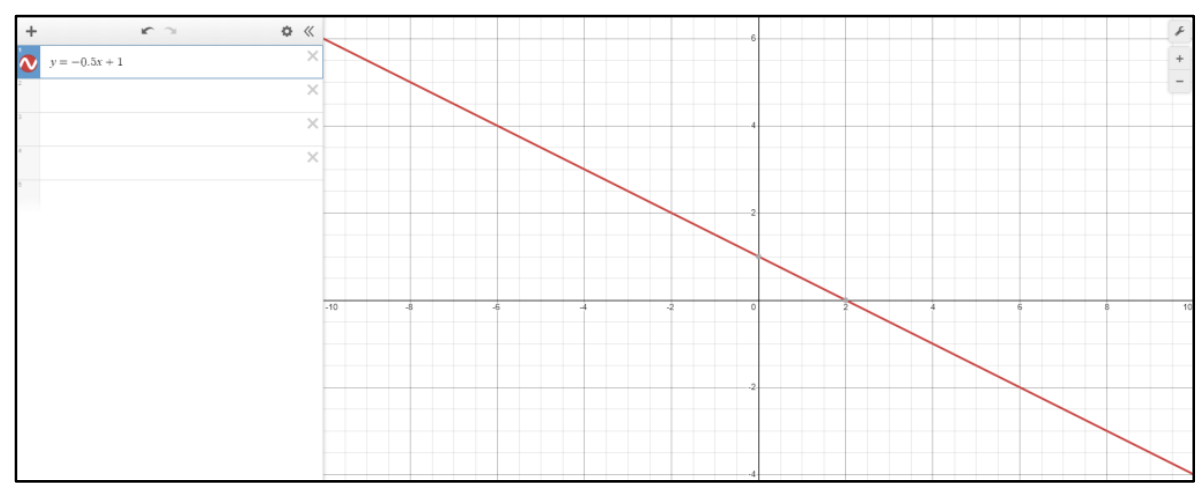

Slika 2. Graf funkcije $\mathrm{f}(\mathrm{x})=-0,5 \mathrm{x}+1$ (Izvor: snimka zaslona www.desmos.com/calculator)

Figure 2. Function graph $\mathrm{f}(\mathrm{x})=-0.5 \mathrm{x}+1$

(Source: screenshot www.desmos.com/calculator)

U oba prikazana slučaja (slike 1 i 2) vidi se da graf funkcije u jednom trenutku siječe os $x$ tj. da je $f(x)=0$. Ta točka se naziva nultočka funkcije. Budući da je os $x$ pravac, a linearna funkcija je također pravac, i pravci se mogu sjeći u samo jednoj točki, onda je jasno da postoji samo jedna nultočka.

Crtanje grafa linearne funkcije može i ne mora biti problem. Uzmimo na primjer funkciju:

$$
f(x)=\frac{1}{3} x+1
$$


Znamo da je pravac jednoznačno definiran sa dvije točke kroz koje prolazi. Dakle, dovoljno je uzeti dvije vrijednosti $x$, izračunati $f(x)$ tj. $y$ te ucrtati te dvije točke i povući pravac kroz njih. Možemo za $x$ uzeti vrijednosti 1 i 2 . Uz određeno naprezanje u mjerenju izračunat ćemo vrijednosti za y koordinatu i nacrtati ćemo graf. Jednom zaxuzmemo da je 0 , a drugi put da je 3. Sada uopće nije problem odrediti točnu poziciju vrijednosti y u koordinatnom sustavu. Naime, znatno je lakše odrediti točke $(0,1)$ i $(3,2)$ nego li točke $(1,4 / 3)$ i $(2,5 / 3)$.

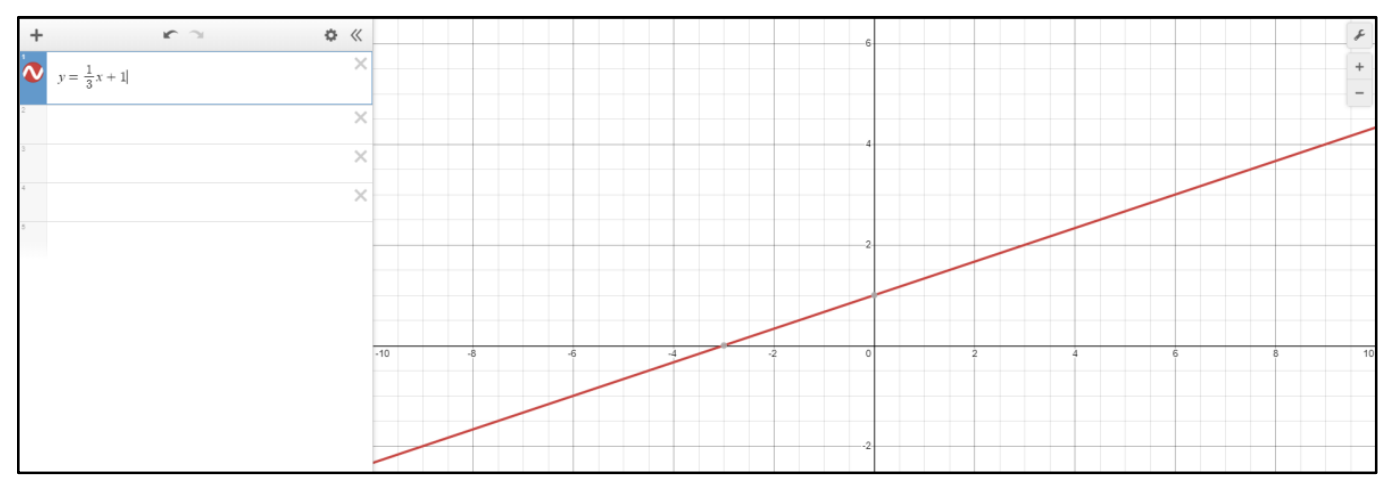

Slika 3. Graf funkcije $f(x)=\frac{x}{3}+1$

(Izvor: snimka zaslona www.desmos.com/calculator)

Figure 3. Function graph

(Source: screenshot www.desmos.com/calculator)

Pretpostavimo da imamo zadatak: Odredi nultočku funkcije $f(x)=-4 \mathrm{x}+8$ i utvrdi je li funkcija rastuća ili padajuća.

Prvo, jer je odmah vidljivo, odredimo da li je rastuća ili padajuća. Koeficijent uz x je negativan, znači da je funkcija padajuća. Sada određujemo nultočku. Dakle:

$$
\begin{aligned}
& f(x)=0 \\
& -4 x+8=0 \\
& -4 x=-8 \\
& x=\frac{-8}{-4} \\
& x_{0}=2
\end{aligned}
$$

Dakle $(2,0)$ je nultočka funkcije.

Određeni problem mogu predstavljati zadaci tipa: Odredi formulu linearne funkcije ako se zna da njen graf prolazi točkama $(-1,3)$ i $(2,6)$.

Znamo da je opći oblik:

$f(x)=k x+l$. 
Zadane točke definiraju:

$f(-1)=3 \mathrm{i}$

$f(2)=6$,

Dakle, dobit ćemo dvije jednadžbe s dvije nepoznanice i to:

$-k+l=3$

$2 k+l=6$

Riješimo sustav jednadžbi na neki već opisani način te dobijemo:

$k=1$,

$l=4$.

Sad se vratimo u početni izraz $f(x)=k x+l$ te zamijenimo ki l dobivenim vrijednostima te imamo:

$f(x)=x+4$

Potražnja nekog dobra na tržištu ovisi o nizu faktora: o cijeni toga dobra, o cijeni drugih dobara na tom tržištu, o dohotku potrošača, tj. o njihovoj kupovnoj moći, navikama, ukusu i strukturi. Funkcija potražnje može biti linearna, kvadratna, eksponencijalna itd. U ovom trenutku ćemo problem pojednostavniti te ćemo matematičko ispitivanje funkcije potražnje svesti na određivanje ovisnosti potražnje nekog dobra o njegovoj cijeni. Ovu linearnu funkciju potražnje ćemo napisati u obliku:

$d(p)=k p+l$

Funkcija potražnje je padajuća funkcija, ne samo u linearnom nego i u općem slučaju.

Primjer 1: Pretpostavimo da se na tržištu nalaze jabuke pri čemu je utvrđen odnos cijene i potražnje prikazan u tablici. Želimo postaviti cijenu od 6 kuna, no ne znamo kakva će tada biti potražnja.

\begin{tabular}{|r|r|r|r|r|}
\hline$p$ & 3 & 5 & 8 & 10 \\
\hline$d$ & 10 & 8 & 7 & 5 \\
\hline
\end{tabular}

Matematički promatrano, potrebno je odrediti funkciju potražnje $d(p)=k p+l$ i izračunati kolika će biti potražnja za cijenu $p=6$. 
Za linearnu funkciju $d(p)=k p+l$ koja najbolje aproksimira skup podataka (točaka) $(3,10),(5,8),(8$, 7), $(10,5)$ potrebno je zapravo dobiti pravac linearne regresije. 3Definiramo najbolju aproksimaciju tj. sa najmanjim odstupanjem zadanih vrijednosti i regresijskih vrijednosti. On se određuje na dolje opisani način.

Naša zadaća jest nalaženje linearne funkcije $\mathrm{y}=\beta_{0}+\beta_{1} \mathrm{x}$ koja najbolje aproksimira skup podataka $\left\{\left(\mathrm{x}_{\mathrm{i}}, \mathrm{y}_{\mathrm{i}}\right): \mathrm{i}=1,2, \ldots, \mathrm{n}\right\}$ tako da zbroj kvadrata odstupanja $\sum_{\mathrm{i}=1}^{\mathrm{n}}\left(\mathrm{y}_{\mathrm{i}}-\beta_{0}-\beta_{1} \mathrm{x}_{\mathrm{i}}\right)^{2}$ bude minimalan. Iz uvjeta minimalnosti dobije se sustav jednadžbi po $\beta_{0}$ i $\beta_{1}$.

$$
\begin{aligned}
& n \beta_{0}+\left(\sum_{i=1}^{n} x_{i}\right) \beta_{1}=\sum_{i=1}^{n} y_{i} \\
& \left(\sum_{i=1}^{n} x_{i}\right) \beta_{0}+\left(\sum_{i=1}^{n} x_{i}^{2}\right) \beta_{1}=\sum_{i=1}^{n} x_{i} y_{i}
\end{aligned}
$$

Budući da imamo 4 podatka (točke), jasno je da je $n=4$. Slijedi:

$$
\begin{aligned}
& \sum_{i=1}^{4} p_{i}=p_{1}+p_{2}+p_{3}+p_{4}=3+5+8+10=26 \\
& \sum_{i=1}^{4} d_{i}=d_{1}+d_{2}+d_{3}+d_{4}=10+8+7+5=30 \\
& \sum_{i=1}^{4} p_{i}^{2}=198 \\
& \sum_{i=1}^{4} p_{i} d_{i}=176 .
\end{aligned}
$$

Slijedi:

$$
\begin{array}{lll}
4 l+26 k=30 & \rightarrow & 2 l+13 k=15 \\
26 l+198 k=176 & \rightarrow & 13 l+99 k=88 .
\end{array}
$$

Rješenje dobivenog sustava jednadžbi dobivamo:

$$
k=-\frac{19}{29}=-0.65 \quad l=\frac{435}{58}=87 .
$$

Prema tome, tražena funkcija potražnje je:

$$
d(p)=-0,65 p+87
$$

\footnotetext{
${ }^{3}$ Osnove matematike u poljoprivredi za stručne studije, str. 99.
} 
Iz toga slijedi da je $d(6)=83,1$ količina robe za cijenu $p=6 \mathrm{kn}$.

Funkcija ponude za razliku od funkcije potražnje, funkcija ponude u pravilu uvijek raste, tj. uvijek je $k>0$, što znači da veće cijene uzrokuju veću ponudu. Linearni oblik glasi: $s(p)=k p+l$.

Ako je npr. analizom tržišta utvrđeno da je ponuda jabuka ovisna o cijeni i dana tablicom, problem se rješava na identični način kao i malo prije prikazani problem potražnje.

Određeni problem, barem na prvi pogled, može predstavljati određivanje točke ravnoteže ponude i potražnje. U biti, taj problem je izuzetno jednostavan jer se zapravo radi o zajedničkoj točki grafa ponude i grafa potražnje, ili, jednostavnije rečeno, o sjecištu ta dva pravca. Potrebno je samo riješiti sustav dviju jednadžbi s dvije nepoznanice i problem točke ravnoteže je riješen.

\section{Kvadratna funkcija}

Definicija: Funkciju $\mathrm{f}: \mathrm{R} \rightarrow \mathrm{R}$ oblika $\mathrm{f}(\mathrm{x})=\mathrm{ax}^{2}+\mathrm{bx}+\mathrm{c}$, gdje su $\mathrm{a}, \mathrm{b}, \mathrm{c} \in \mathrm{R}$ i a različito od 0 nazivamo kvadratnom funkcijom.

Osim skupa realnih brojeva u matematici se služimo i skupom kompleksnih brojeva. Algebarski prikaz tog broja je $z=a+b i$, gdje je $a$ realni dio od $z$, a $b$ imaginarni dio od $z$. Imaginarna jedinica $i$ ima svojstvo $i^{2}=-1$.

Sada možemo definirati skup kompleksnih brojeva:

$\mathbf{C}=\{a+b i \mid a, b \in \mathbf{R}\}$.

Graf svake kvadratne funkcije je krivulja koja se zove parabola.

Nakon ove digresije, može se vratiti na problem kvadratne jednadžbe. Dakle, jednadžba oblika $a x^{2}+b x+c=0(a \neq 0, b$ i $c \in R)$ naziva se kvadratna jednadžba u polju R. Svaki broj x (realni ili kompleksni) koji zadovoljava tu jednadžbu naziva se rješenje kvadratne jednadžbe.

Kod kvadratne jednadžbe $a x^{2}+b x+c=0$ pojavljuju se sljedeći koeficijenti:

$a$ - vodeći koeficijent

$b-$ linearni koeficijent

$c$ - slobodni koeficijent

Rješenja kvadratne jednadžbe nalazimo pomoću formula: $x_{1,2}=\frac{-b \pm \sqrt{b^{2}-4 a c}}{2 a}$.

Navest ćemo opći postupak crtanja grafa i određivanja bitnih elemenata (svojstava) funkcije 
$f(x)=a x^{2}+b x+c$.

1. Funkcija je definirana za $\forall x \in \boldsymbol{R}$

2. Kvadratna funkcija $f(x)=a x^{2}+b x+c$ ima ekstrem $u$ točki s apscisom $x_{0}=-\frac{b}{2 a}$. Vrijednost ekstrema iznosi $y_{0}=\frac{4 a c-b^{2}}{4 a}$, i ekstrem je minimum ako je $a>0$, odnosno maksimum ako je $\mathrm{a}<0$.

Točku $\mathrm{T}\left(\mathrm{x}_{0}, \mathrm{y}_{0}\right)$ zovemo tjeme parabole.

3. Nultočke određujemo rješavanjem pripadne jednadžbe $a x^{2}+b x+c=0$

- ako su $x_{1} i_{x}$ različiti realni brojevi tada graf siječe $\mathrm{x}$ os na ta dva mjesta;

- ako je $\mathrm{x}_{1}=\mathrm{x}_{2}$ graf dodiruje $\mathrm{x}$ os;

- ako su $x_{1}$ i $x_{2}$ kompleksni brojevi, tada graf niti siječe niti dodiruje $\mathrm{x}$ os.

Na donjim slikama imamo primjere grafova od dvije kvadratne funkcije. Prvo ćemo uzeti $f(x)=x^{2}$, te potom i $\mathrm{f}(\mathrm{x})=3 \mathrm{x}^{2}$. Vidimo da što je veća vrijednost koeficijenta $a$ to je graf "uži".

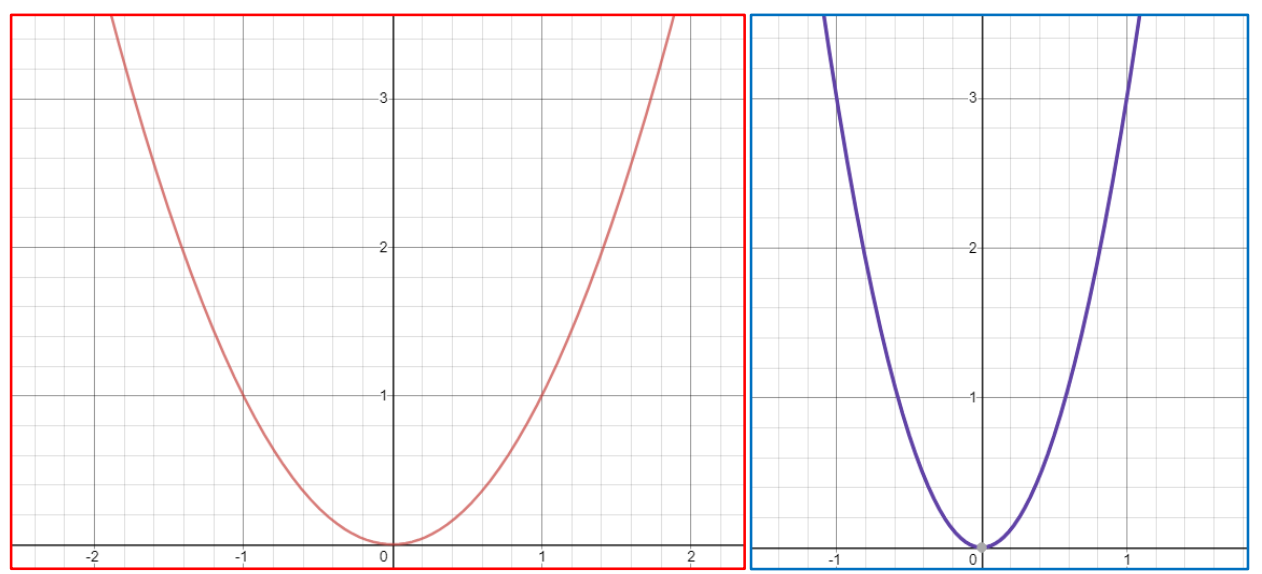

Slika 4. Graf funkcije $f(x)=x^{2}$ i $f(x)=3 x^{2}$

(Izvor: snimka zaslona www.desmos.com/calculator)

Figure 4. Function graph $f(x)=x^{2}$ and $f(x)=3 x^{2}$

(Source: screenshot www.desmos.com/calculator)

Uzmimo na primjer funkciju:

$$
f(x)=x^{2}+2 x-1
$$

iz nje vidimo da je: $\mathrm{a}=1 ; \mathrm{b}=2 ; \mathrm{c}=-1$

Kad te vrijednosti uvrstimo u izraze

$x_{1}=\frac{-b+\sqrt{b^{2}-4 a c}}{2 a}, \quad x_{2}=\frac{-b-\sqrt{b^{2}-4 a c}}{2 a}$ 
dobit ćemo da je: $x_{1}=-2,415 ; x_{2}=0,414$ što predstavlja približne decimalne vrijednosti nultočki naše funkcije. Uvrštavanjem u točku tjemena dobivamo $T(-1,-2)$. Uzimajući da je $a=1>0$ imamo graf zadane funkcije na slici 5.

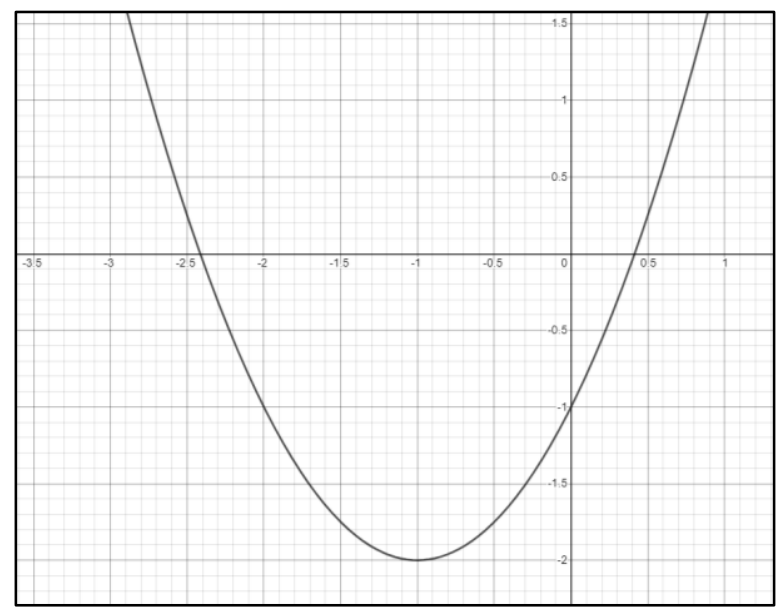

Slika 5. Graf funkcije $\mathrm{f}(\mathrm{x})=\mathrm{x}^{2}+2 \mathrm{x}-1$

Figure 5. Function graph $\mathrm{f}(\mathrm{x})=\mathrm{x}^{2}+2 \mathrm{x}-1$

Pretpostavimo da treba riješiti sljedeći zadatak koji glasi: nacrtaj graf funkcije $f(x)=x^{2}+9$.

Vidimo da su koeficijenti: $a=1 ; b=0 ; c=9$

Budući da je a $>0$ funkcija ima minimum. Nadalje, lako je odrediti i poziciju tjemena tj. tjeme je u točki $\mathrm{T}(0,9)$. Pristupamo rješavanju $\mathrm{x}_{1} \mathrm{i} \mathrm{x}_{2} \mathrm{i}$ dobivamo sljedeći rezultat:

$\mathrm{x}_{1}=3 \mathrm{i} \quad \mathrm{x}_{2}=-3 \mathrm{i}$

Pojavljuje se blokada. $O K$, imamo $\mathrm{x}_{1} \mathrm{ix}_{2}$, ali gdje ih ucrtati? Jednostavno, nigdje. Ovaj rezultat zapravo pokazuje da graf ne sječe os $\mathrm{x}$. Graf ćemo nacrtati tako što uz poznato tjeme uzmemo još dvije točke (npr. za x $=-1$ i $x=1$ ) izračunamo y te kroz njih položimo parabolu.

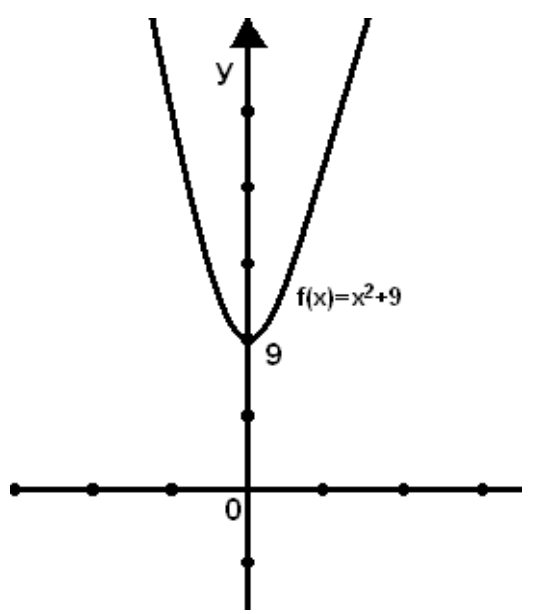

Slika 6. Graf funkcije $f(x)=x^{2}+9$ (Izvor: Zrno, 2007)

Figure 6. Function graph $f(x)=x^{2}+9$ (Source: Zrno, 2007) 
U poljoprivredi postoje različiti postupci koji se ne mogu povezati s linearnom funkcijom već se odvijaju po nekoj krivulji, vrlo često paraboli. Može se raditi o vrenju vina ili piva, sušenju voća ili povrća i brojnim drugim procesima. Koliko god je važna temperatura, važno je i vrijeme.

Primjer 2. Pretpostavimo da postoji proces koji se odvija po nekoj kvadratnoj funkciji $s(t)=-t^{2}+8 t$ i potrebno je naći trenutak kad je u vrhuncu (npr. vrhunac vrenja); ( $t$ vrijeme u danima). Uz poznatu zakonitost (funkciju) dovoljno je odrediti maksimum te funkcije. U ovom primjeru bi imali: $a=-1$; $b=8 ; c=0$

$t_{0}=-\frac{b}{2 a}=-\frac{8}{-2}=4$.

Dakle, ovaj tehnološki proces u četvrtom danu će postići svoj vrhunac.

Kad je bilo govora o linearnim funkcijama, spomenulo se problem ponude i potražnje. Naglašeno je da je taj problem rijetko linearne prirode.

Primjer 3. Uzmimo na primjer da je potražnja dana s podacima u tablici i da je pri tome u pitanju kvadratna funkcija.

\begin{tabular}{|l|r|r|r|}
$p$ & 4 & 8 & 12 \\
\hline$d$ & 200 & 120 & 20
\end{tabular}

Treba odrediti odgovarajuću formulu funkcije potražnje za podatke iz dane tablice.

Opći oblik je: $\mathrm{f}(\mathrm{x})=\mathrm{ax} \mathrm{x}^{2}+\mathrm{bx}+\mathrm{c}$

U ovom slučaju može se pisati: $d(p)=a p^{2}+b p+c$. Problem je što ne znamo vrijednosti $a, b, c$ no to se može riješiti. Za početak, uvrstimo brojeve iz tablice u polaznu funkciju. Dobivamo:

$d(4)=200 \quad \Rightarrow \quad 16 a+4 b+c=200$

$d(8)=120 \quad \Rightarrow \quad 64 a+8 b+c=120$

$d(12)=20 \quad \Rightarrow \quad 124 a+12 b+c=20$

Uočava se sustav od tri jednadžbe s tri nepoznanice. Lako se izračunaju. Kao rezultate toga dobivamo:

$a=-\frac{5}{8}, b=-\frac{25}{2}, c=260$.

Tražena funkcija potražnje glasi: $d(p)=-\frac{5}{8} p^{2}-\frac{25}{2} p+260$. 
Sada, kad postoje koeficijenti uz varijablu p, više nije problem nacrtati odgovarajući graf te iz njega vidjeti kretanje potražnje tj. njihovu međuovisnost.

\section{Eksponencijalna funkcija}

Definicija: Neka je zadan realan broj a takav da je a $>0$ i $a \neq 1$. Funkciju $\mathrm{f}: \mathrm{R} \rightarrow \mathrm{R}^{+}$, oblika $\mathrm{f}(\mathrm{x})=\mathrm{a}^{\mathrm{x}}$ nazivamo eksponencijalna funkcija.

Razlikuju se dva slučaja:

$$
\begin{gathered}
a>1 ; \\
0<a<1
\end{gathered}
$$

Uzmimo na primjer graf funkcije $f(x)=3^{x}$. Odmah je uočljivo da je $a>1$, točnije $a=3$. Za potrebe određivanja točaka kroz koje graf prolaziti uzet ćemo tablicu s proizvoljnim vrijednostima $\mathrm{x}$ te ćemo izračunati odgovarajuće vrijednosti $\mathrm{f}(\mathrm{x})$.

\begin{tabular}{|c|c|c|c|c|c|}
\hline$x$ & -2 & -1 & 0 & 1 & 2 \\
\hline$f(x)$ & $\frac{1}{9}$ & $\frac{1}{3}$ & 1 & 3 & 9 \\
\hline
\end{tabular}

Kad te točke unesemo u koordinatni sustav, dobit ćemo sljedeći graf:

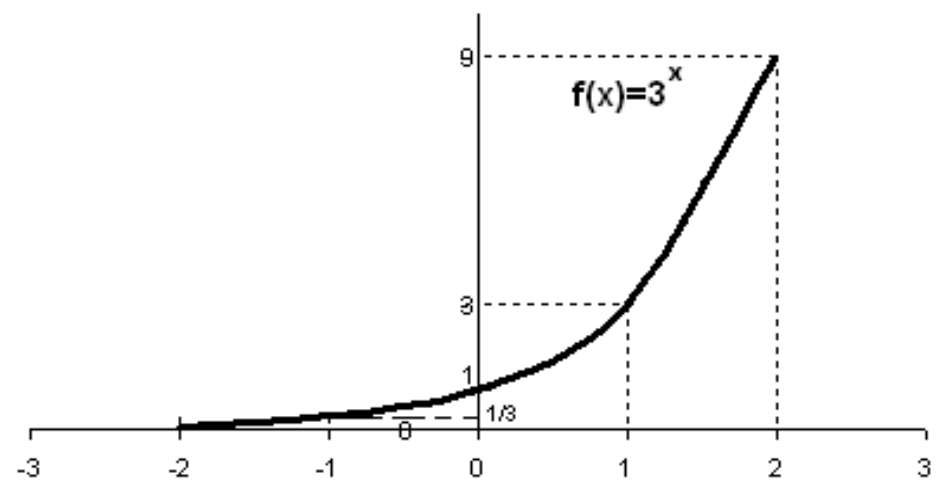

Slika 7. Graf funkcije $f(x)=3^{x}$, pri čemu je $a>1$ (Izvor: Zrno, 2007)

Figure 7. Function graph $f(x)=3^{x}, a>1$ (Source: Zrno, 2007)

Sada se kao drugi primjer može uzeti funkcija kod koje je $0<\mathrm{a}<1$. Dakle, potrebno je nacrtati graf funkcije:

$$
f(x)=\left(\frac{1}{2}\right)^{x}
$$

Kao i u prethodnom slučaju, napraviti ćemo tablicu s proizvoljnim vrijednostima $\mathrm{x}$ te ćemo izračunati vrijednosti $f(x)$

\begin{tabular}{|c|c|c|c|c|c|}
\hline$x$ & -2 & -1 & 0 & 1 & 2 \\
\hline$f(x)$ & 4 & 2 & 1 & $1 / 2$ & $1 / 4$ \\
\hline
\end{tabular}


Unijeti ćemo dobivene točke u koordinatni sustav i nacrtati ćemo graf te funkcije.

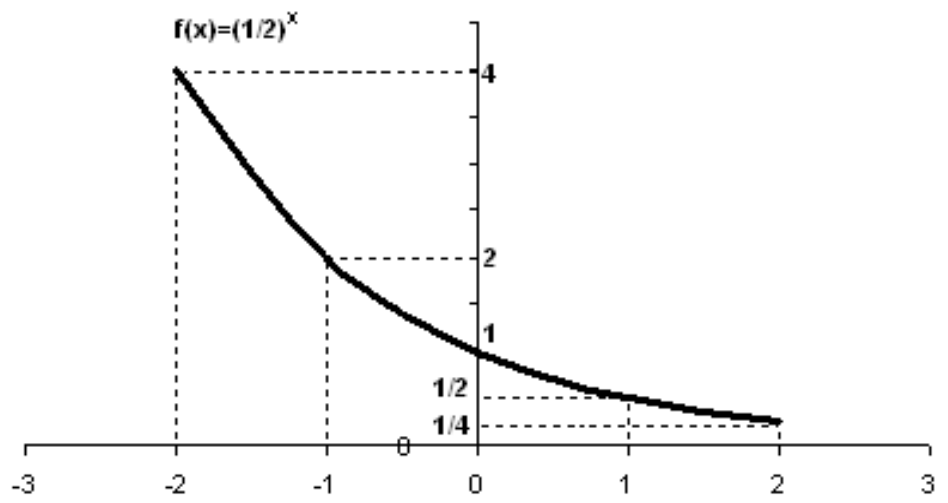

Slika 8. Graf funkcije $f(x)=\left(\frac{1}{2}\right)^{x}$ pri čemu je $0<a<1$ (Izvor: Zrno, 2007)

Figure 8. Function graph $f(x)=\left(\frac{1}{2}\right)^{x}, 0<a<1$ (Source: Zrno, 2007)

Općenito imamo sljedeća osnovna svojstva eksponencijalne funkcije $f(x)=a^{x}$ :

- funkcija je definirana za svaki realan broj $x$

- funkcija poprima samo pozitivne vrijednosti, tj. $f(x)>0, \forall x \in \boldsymbol{R}$.

- ako je $a>1$, funkcija je rastuća, a ako je $0<a<1$, funkcija je padajuća.

Ako je baza $a=e=2,718 \ldots$ ( $e$ je Eulerov broj), tada funkciju $f(x)=e^{x}$ zovemo prirodna eksponencijalna funkcija. Često se primjenjuje u ekonomiji kod izračuna prirodnog prirasta.

U poljoprivredi se eksponencijalnom funkcijom može prikazati razvoj bolesti biljaka koje su uzrokovane bakterijama. Naime, bakterije se razmnožavaju binarnom diobom, određenim oblikom mitoze (od jedne bakterije, njezinim "razdvajanjem" nastaju dvije nove bakterije).

Primjer 4. U početku je jedna, te nakon nekog vremena imamo dvije bakterije. Potom, nakon istog vremenskog intervala 4, pa 8, pa 16,32, 64 itd. Upravo zbog brzine ovog razvoja bakterijska oboljenja su izuzetno opasna. Činjenica jest da se može boriti protiv njih no potrebno je brzo reagirati jer problem može izmaći kontroli. Naime, pretpostavimo da za proces mitoze treba 5 minuta. Uz pomoć eksponencijalne funkcije možemo izračunati koliko će biti bakterija nakon jednog dana. Kako riješiti taj zadatak?

Prvo, proučimo povećanje broja bakterija u vezi s vremenom.

$t=0 \rightarrow 1$ bakterija $=2^{0}-$ nulti, polazni trenutak

$t=1 \rightarrow 2$ bakterije $=2^{1}-$ kraj prvog vremenskog intervala

$t=2 \rightarrow 4$ bakterije $=2^{2}-$ kraj drugog vremenskog intervala

$t=3 \rightarrow 8$ bakterije $=2^{3}-$ kraj trećeg vremenskog intervala

$t=4 \rightarrow 16$ bakterije $=2^{4}-$ kraj četvrtog vremenskog intervala

Očito je da se broj bakterija mijenja po eksponencijalnoj funkciji gdje je baza broj 2, a eksponent je broj vremenskih intervala. Dakle, funkcija bi imala oblik: $f(t)=2^{t}$. 
Ako je interval razmnožavanja 5 minuta, u jednom satu će se ciklus ponoviti 12 puta, a tijekom 24 sata odvilo se 288 ciklusa.

\begin{tabular}{|l|l|l|l|l|l|}
\hline $\mathrm{t}$ & 0 (početak) & $12(1$ sat $)$ & $60(5$ sati) & 144 (12 sati) & 288 (24 sata) \\
\hline \multirow{2}{*}{$f(\mathrm{t})$} & $2^{0}$ & $2^{12}$ & $2^{60}$ & $2^{144}$ & $2^{288}$ \\
\cline { 2 - 6 } & 1 & 4096 & $1,15^{*} 10^{18}$ & $2,23 * 10^{43}$ & $4,97 * 10^{86}$ \\
\hline
\end{tabular}

Podaci koji su prikazani u tablici nisu pogodni za crtanje grafa ali daju uvid u broj bakterija. Zapravo, ovi brojevi ukazuju na zastrašujuću progresivnost bakterijskog oboljenja. Ako se ipak želi nacrtati graf te funkcije, zbog "prostornih problema", može se ograničiti samo na prva 3 - 4 ciklusa.

\section{Logaritamska funkcija}

$\log _{b} a=\mathrm{c} \Leftrightarrow b^{c}=\mathrm{a}(\mathrm{a}>0, \mathrm{~b}>0$ i $\mathrm{b} \neq 1)$

Logaritam od $a$ po bazi $b$ je eksponent $c$ kojim treba potencirati bazu $b$ kako bi se dobio broj $a$. Na primjer:

$\log _{2} 4=2$ jer je $2^{2}=4$

$\log _{3} \frac{1}{9}=-2$ jer je $3^{-2}=\frac{1}{9}$

$\log _{7} 1=0 \quad$ jer je $\quad 7^{0}=1$.

$\log _{5} 5=1 \quad$ jer je $\quad 5^{1}=5$.

Definicija: Funkciju f: $\mathrm{R}^{+} \rightarrow \mathrm{R}$ oblika $\mathrm{f}(\mathrm{x})=\log _{\mathrm{a}} \mathrm{x}$, gdje je a $>0$ i $a \neq 1$, nazivamo logaritamskom funkcijom po bazi a.

Slično eksponencijalnoj funkciji, i ovdje postoje dva slučaja i to kad je:

a) $a>1 \mathrm{i}$

b) $0<a<1$.

Uzmimo kao prvi primjer graf funkcije $\mathrm{f}(\mathrm{x})=\log _{3} \mathrm{x}$. Budući da je logaritamska funkcija inverzna eksponencijalnoj, prvo radimo tablicu vrijednosti eksponencijalne funkcije (odgovarajuće s bazom 3):

\begin{tabular}{|l|l|l|l|l|l|}
$x$ & -2 & -1 & 0 & 1 & 2 \\
\hline $3^{x}$ & $1 / 9$ & $1 / 3$ & 1 & 3 & 9
\end{tabular}

Zbog inverznosti logaritamske i njene odgovarajuće eksponencijalne funkcije, potrebno je zamijeniti (obrnuti) retke prethodne tablice:

\begin{tabular}{|l|l|l|l|l|l|}
$X$ & $1 / 9$ & $1 / 3$ & 1 & 3 & 9 \\
\hline$f(x)$ & -2 & -1 & 0 & 1 & 2
\end{tabular}


Sada unosimo točke u koordinatni sustav i dobivamo sljedeći graf (graf zadane logaritamske funkcije):

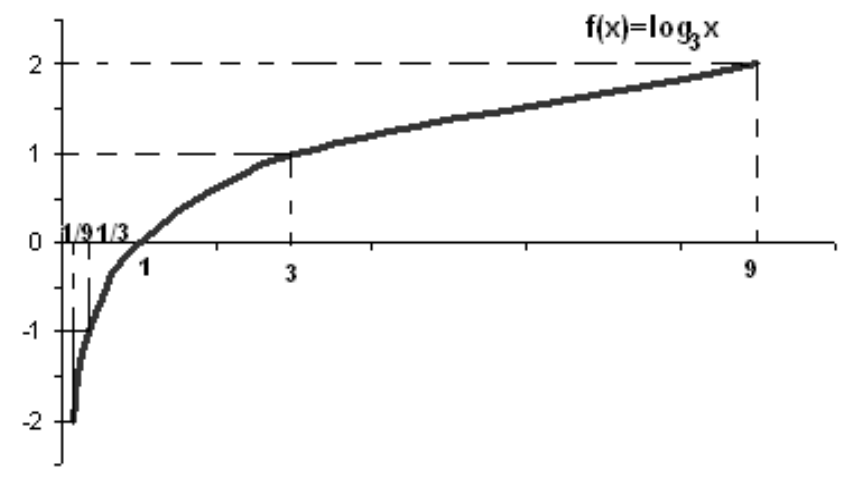

Slika 9. Graf funkcije $f(x)=\log _{3} x$ (Izvor: Zrno, 2007)

Figure 9. Function graph $f(x)=\log _{3} x$ (Source: Zrno, 2007)

Sljedeći primjer, u kojem je $0<\mathrm{a}<1$, može biti funkcija, odnosno graf funkcije $\mathrm{f}(\mathrm{x})=\log _{\frac{1}{2}} \mathrm{x}$

Ponovno, kao kod prethodnog primjera prvo se radi tablicu:

\begin{tabular}{|l|l|l|l|l|l|}
$x$ & -2 & -1 & 0 & 1 & 2 \\
\hline$(1 / 2)^{x}$ & 4 & 2 & 1 & $1 / 2$ & $1 / 4$
\end{tabular}

te potom i tablicu za zadanu funkciju:

\begin{tabular}{|l|l|l|l|l|l|}
$x$ & $1 / 4$ & $1 / 2$ & 1 & 2 & 4 \\
\hline$f(x)$ & 2 & 1 & 0 & -1 & -2
\end{tabular}

Sada unosimo točke u koordinatni sustav i dobivamo sljedeći graf (graf zadane logaritamske funkcije):

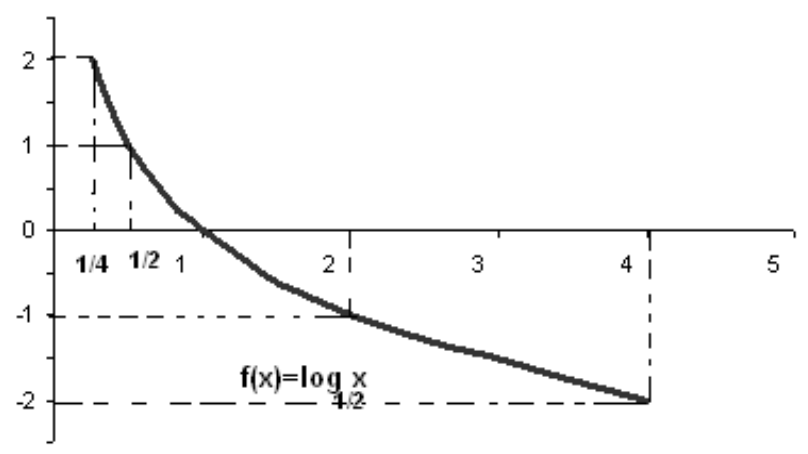

Slika 10. Graf funkcije $f(x)=\log _{\frac{1}{2}} x$ (Izvor: Zrno, 2007)

Figure 10. Function graph (Source: Zrno, 2007)

Općenito imamo sljedeća svojstva logaritamske funkcije $f(x)=\log _{a} x$ : 
- definirana je za pozitivne realne brojeve $(\mathbf{R}+)$;

- poprima sve realne vrijednosti;

- rastuća je ako je a $>1$, odnosno padajuća ako je $0<\mathrm{a}<1$.

Usporedimo grafove eksponencijalne funkcije $f(x)=3^{x}$ l logaritamske funkcije $f(x)=\log _{3} x$

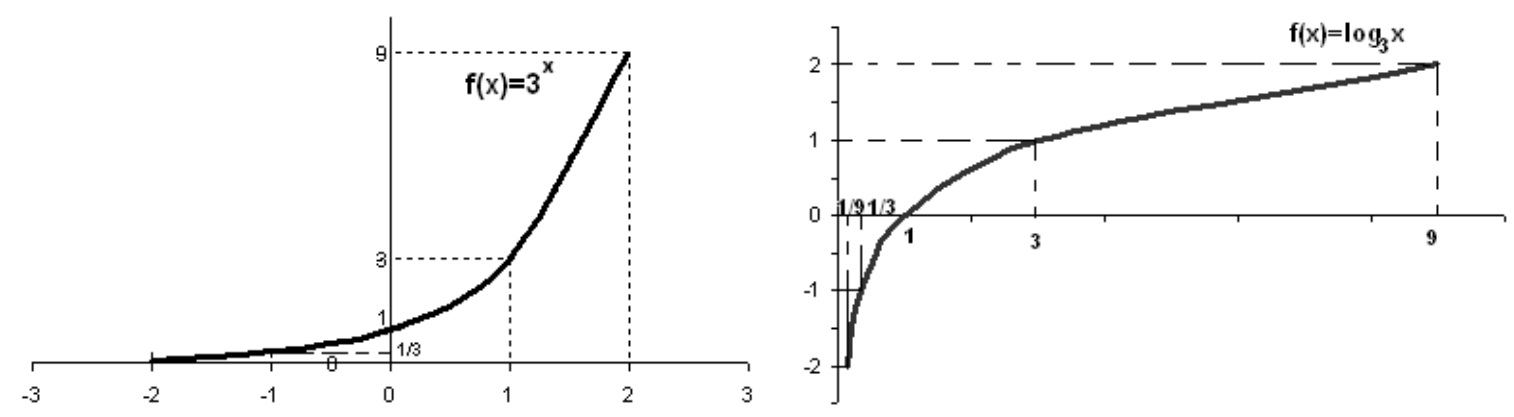

Slika 11. Grafovi funkcije $f(x)=3^{x} \mathrm{i} f(x)=\log _{3} x$ (Izvor: Zrno, 2007)

Figure 11. Function graph $f(x)=3^{x}$ and $f(x)=\log _{3} x$ (Source: Zrno, 2007)

Može se uočiti da su ovi grafovi međusobno osno simetrični likovi u odnosu na pravac $y=x$ (simetrala prvog i trećeg kvadranta). Zapravo, općenito su grafovi logaritamske funkcije $\mathrm{f}(\mathrm{x})=$ $\log _{\mathrm{a}} \mathrm{x}$ i eksponencijalne $\mathrm{g}(\mathrm{x})=\mathrm{a}^{\mathrm{x}}$ Zrcalno simetrični likovi $\mathrm{u}$ odnosu na pravac $\mathrm{y}=\mathrm{x}$.

Logaritamsku funkciju kojoj je baza $a=e=2,718 \ldots$ (e je Eulerov broj) zovemo prirodna logaritamska funkcija i označavamo $\ln x$.

Kad se promatralo eksponencijalnu funkciju uočilo se da tijekom "vremena" (vrijednosti na osi x) dolazi do izuzetno velikog porasta (vrijednosti na osi y) i to se u primjeru povezalo s razmnožavanjem bakterija. Promatrajući logaritamsku funkciju vidi se da u početku dolazi do velikih pomaka (rasta vrijednosti po osi y) no kako vrijeme više prolazi (os x) rast se usporava, gotovo staje. Takvo kretanje se može povezati s tovom životinja. Odojak će imati u startu npr. $5 \mathrm{~kg}$, nakon 6 mjeseci će doći do 150 kg, nakon godinu dana će imati $180 \mathrm{~kg}$, a nakon još 5 godina će doći do $200 \mathrm{~kg}$. Jasno, ovi podaci su karikirani no cilj im je ukazati na "usporavanje", na kretanje po logaritamskoj funkciji.

Primjer 5. Pretpostavimo da postoji neka realna funkcija vezana uz tov određene vrste životinja i da glasi $s(t)=2 \log _{2} t+5$. U tom slučaju ne bi trebao biti poseban problem odrediti tjelesnu masu tovljene životinje nakon 32 dana (32 dana je namjerno uzeto jer je $32=2^{5}$ ) ili pak nacrtati dijagram "debljanja" životinje.

Za početak će se napraviti sljedeća tablica: 


\begin{tabular}{|l|l|l|l|}
$t$ & 0 & 1 & 2 \\
\hline $2^{t}$ & 1 & 2 & 4
\end{tabular}

Za vrijednosti vezane uz vrijeme namjerno nisu uzeti negativni brojevi jer bi to značilo da se prati tjelesnu masu životinje prije nego li je uopće okoćena. Vrijeme 0 je trenutak koćenja životinje.

Sada prethodnu tablicu transformiramo u sljedeći oblik:

\begin{tabular}{|l|l|l|l|}
$X$ & 1 & 2 & 4 \\
\hline $\log _{2} t$ & 0 & 1 & 2 \\
\hline $2 \log _{2} t$ & 0 & 2 & 4 \\
\hline $2 \log _{2} t+5$ & 5 & 7 & 9
\end{tabular}

Uz ove podatke nije problem nacrtati graf funkcije.

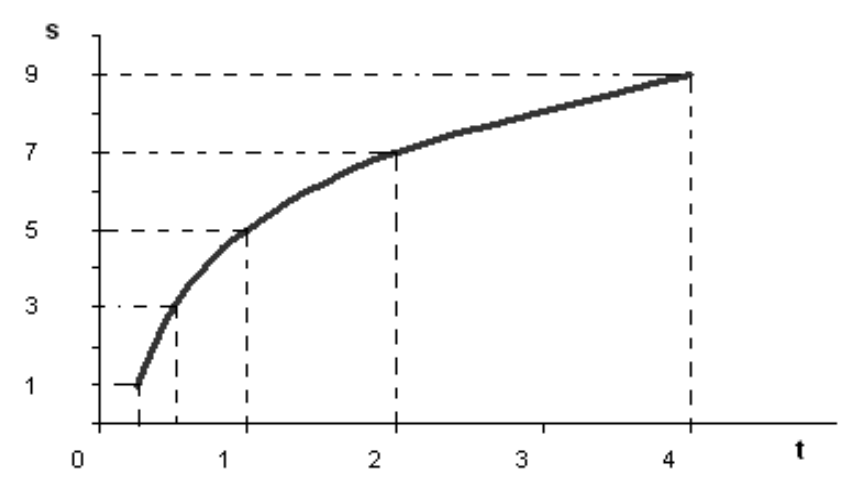

Slika12. Grafovi funkcije $\mathrm{s}(\mathrm{t})=2 \log _{2} \mathrm{t}+5$ (Izvor: Zrno, 2007)

Figure 12. Function graph $\mathrm{s}(\mathrm{t})=2 \log _{2} \mathrm{t}+5$ (Source: Zrno, 2007)

Računanje tjelesne mase životinje nakon 32 dana nije problem.

$\mathrm{s}(32)=2 \log _{2} 32+5=2 \cdot 5+5=10+5=15$

\section{Zaključak}

Čovjek je u početku bio nomad, sakupljač i lovac. U jednom trenutku, vjerojatno slučajno, otkrio je da nema potrebe sakupljati plodove biljaka i loviti životinje već da ih može i uzgajati. Iako nije imao pojma o matematici, dok je crtao po zidovima pećine, shvatio je da ako ima više zemlje ili stoke može proizvesti više hrane. Počeo je "matematički" razmišljati.

Tijekom godina razvijala se matematika. Međutim, ona nije bila sama sebi svrha, ona je bila primjenjiva na svakodnevni život. Određeni problem je bila pismenost tj. educiranost stanovništva i 
dostupnost informacija no $\mathrm{i}$ to je tijekom vremena savladano. Dakle, današnja ekspanzija poljoprivredne proizvodnje nije slučajna. Ona je posljedica primjene matematike.

Kad je u pitanju poljoprivreda, dijelovi matematike jesu primjenjivi. Stoga je u radu prikazan dio matematike koji se najčešće pojavljuje u poljoprivredi, ili točnije, pomoću kojeg se rješavaju najčešći problemi u poljoprivredi. Mnogi procesi u poljoprivredi imaju svoje zakonitosti u kojima se uspostavlja veza između dvije varijable tj. imamo funkcionalnu ovisnost. Obrađene su tipične elementarne funkcije: linearna, kvadratna, eksponencijalna i logaritamska i dani neki primjeri njihovih primjena. Pri tome je poseban naglasak stavljen na grafove funkcija i njihovu analizu jer je pomoću njih, zbog njihove "vidljivosti", izuzetno lako uočiti neka kretanja i eventualne probleme. Nadamo se da smo kod čitatelja pobudili veći interes za matematiku koja se može primijeniti na poljoprivredu.

\section{Zahvala}

Rad je nastao u okviru izrade Završnog rada, diplomantice Ivane Pintur na Veleučilištu "Marko Marulić" u Kninu, 2019. godine: Primjena elementarnih funkcija u poljoprivredi.

\section{Literatura}

Dakić, B., Elezović, N. (2004). Matematika 2. Zagreb: Element.

Pintur, I. (2019). Primjena elementarnih funkcija u poljoprivredi, Završni rad, Veleučilište "Marko Marulić" u Kninu.

Schumacher E., (2005). Matematika za agronome. Zagreb: interna skripta Agronomski fakultet Sveučilišta u Zagrebu.

Zrno, Ž. (2007). Osnove matematike u poljoprivredi za stručne studije. Knin: Veleučilište "Marko Marulić" u Kninu.

https://ucimmatematiku.wordpress.com/2014/09/02/pojam-skupa-elementi

https://www.desmos.com/calculator

Primljeno: 05. prosinca 2019. godine

Received: December 05, 2019

Prihvaćeno: 30. prosinca 2019. godine

Accepted: December 30, 2019 